\title{
Estimating Intermolt Duration in Giant Crabs (Pseudocarcinus gigas)
}

\section{Caleb Gardner}

Tasmanian Aquaculture and Fisheries Institute, University of Tasmania, Tasmania, Australia

\author{
Andrew Jenkinson and Hendrik Heijnis \\ Australian Nuclear Science and Technology Organisation, Australia
}

\section{Abstract}

Estimates of intermolt duration of giant crabs, based on tag-recapture methodology, are used in evaluating management options. However, several shortcomings of tag-recovery data have been noted, including the low number of tags inserted in legal-sized animals and the long periods of time-at-large which require an unusually long intermolt duration. This led to the evaluation of alternative methods to estimate intermolt duration. Reproduction in female giant crabs occurs in annual cycles, although females occasionally "skip" a reproductive season and do not become ovigerous; it has been noted previously that this appears to be associated with molting. Thus the proportion of females that do not participate in reproduction may indicate the proportion molting. We tried this approach with a sample of 342 females and measured the number that were "skipping" a reproductive season by computerized tomography scanning (CT-scanning) of their ovaries prior to the extrusion of eggs. From the inferred proportion molting, intermolt duration was estimated at 9 years for mature size classes; however, 95\% confidence limits were broad (6.8-13.1 years). This estimate does, however, corroborate those previously reported from studies in which tag and recapture methods were employed. Radiometric aging $\left.{ }^{228} \mathrm{Th} /{ }^{228} \mathrm{Ra}\right)$ of carapaces was also undertaken with the focus of this work on testing an assumption of the method, rather than describing the intermolt duration of a population. We tested the assumption that there is negligible exchange of radionuclides during intermolt in the exoskeleton, which is critical for reliable estimation of intermolt. SEM images of the internal structure of the exoskeleton indicated that exchange of material within the exoskeleton was unlikely and the majority of radiometric assays were consistent with this observation. Radiometric age was estimated 
by gamma spectroscopy, which allowed rapid analysis compared to previously reported methodology. This rapid processing may facilitate broader application of radiometric aging to crustacean research.

\section{Introduction}

Giant crabs (Pseudocarcinus gigas) are fished across southern Australia in a small fishery based on high value live product. The fishery developed only within the last decade, with negligible catch prior to 1991 (Gardner 1998a). As a result, management is rudimentary in comparison to more established fisheries in the region, notably that for the southern rock lobster (Jasus edwardsii). Although considerable research has been expended on giant crabs, more information is required on their biology, including growth. Growth influences most basic fisheries analyses, such as yieldand egg-per-recruit analyses, and is thus a high priority area for research.

General observations on molting of giant crabs were reported by Levings et al. (1996). They reported that males molt more frequently than females, molting occurs in cycles longer than 1 year, and females produce broods over a range of instars (that is, there is no terminal molt to maturity).

Growth in crustaceans is a function of both the increase in size at molt (molt increment) and the frequency of molting (intermolt duration). Molt increment in giant crabs has been estimated using data collected through field based tag-recapture work with methods discussed by Levings et al. (1996). McGarvey et al. (1999, in press) modeled molt increment from the 350 recaptures in this data set that had molted at least once and quantified significant differences in spatial patterns among both sexes in four states. They noted that estimates of intermolt duration from tag recoveries require larger sample sizes than for quantifying the distribution of molt increments. This is because of the uncertainty around the time prior to the last molt for each crab tagged or recaptured.

Estimates of mean female intermolt by McGarvey et al. (in press) ranged from 4.5 years for immature females of $120 \mathrm{~mm}$ carapace length (CL) to 15 years for mature females of $180 \mathrm{~mm} \mathrm{CL}$. These estimates were based on a discrete normal likelihood estimator, mean intermolt period modeled as a quadratic polynomial of premolt length. The analysis pooled all recaptures over a 5-year period from across southern Australia, as there were insufficient data to differentiate regional trends. This analysis of tag-recapture data for intermolt duration by McGarvey et al. (1999) has been used in assessing management of the Australian giant crab fishery, notably showing that the current legal minimum length for females is conservative, protecting about $50 \%$ of virgin population egg production. However, several shortcomings of tag recovery data from commercial fisheries in giant crabs are noted. For instance, although most of the Australian catch is taken in Tasmania, only 14 recaptures that had molted were recorded from this state, with only 2 of these from males. Limitations of tagging for estimating intermolt duration of giant crabs are threefold: (1) Because 
giant crabs are high value and numbers captured are low, tags inserted in the course of commercial fishing operations have been placed almost solely in giant crabs that are protected and must therefore be legally returned to the sea. These are crabs below the legal minimum length of $150 \mathrm{~mm} \mathrm{CL}$, and ovigerous females. Tags have thus rarely been placed in legal size animals. (2) The unusually long intermolt duration of giant crabs requires corresponding long times-at-large. (3) Uncertainty remains, as with all tag-recovery intermolt period estimators, about the time back to the most recent molt prior to first capture.

We assessed three alternative methods for study of growth in giant crabs: (1) inferring the proportion of the population molting based on the proportion of females participating in reproduction; (2) radiometric aging of the exoskeleton; and (3) lipofuscin aging. Although lipofuscin aging is a relatively new technique, it has been studied intensively and methods are described in detail elsewhere (Sheehy 1992, Wahle et al. 1996, Sheehy et al. 1998). Consequently, in this paper we focus on the first two methods, which have been applied less widely.

\section{Reproductive State of Females}

Female giant crabs produce clutches of eggs in annual cycles with females extruding eggs in late autumn that hatch in spring, although not all females participate in egg production each year (Levings et al. 1996, Gardner 1997). "Skipping" of reproduction by females may occur in years before or after molting, based on observations in tank trials and also through comparing fouling state of shells with ovigerous state of females (Gardner 1998b, McGarvey et al. 1999). This relationship between molting and skipping of reproduction implies that a measure of intermolt duration could be obtained from the proportion of females skipping reproduction in any 1 year. For instance, if half the population were found to skip reproduction in any 1 year, it would suggest that molting occurred every 2 years.

\section{Radiometric Aging}

Research on the radiometric aging of calcified biological structures has been undertaken sporadically for several decades with several studies focused on crustaceans (Bennett and Turekian 1984, Le Foll et al. 1989, Nevissi et al. 1996). The application of radiometric aging to crustaceans is based on the incorporation of radium ${ }^{228} \mathrm{Ra}$ ) with calcium into the exoskeleton after molting; this radium thereafter decays to thorium $\left({ }^{228} \mathrm{Th}\right)$. Several methods to measure nuclear decay in biological samples have been described including alpha-spectroscopy, thermal ionization mass spectrometry, and gamma-spectroscopy (Bennett and Turekian 1984, Reyss et al. 1995, Andrews et al. 1999). Various methods differ in the accuracy of their age estimation and also in time and expense required to process samples; however, the fundamental principle for the estimation of age through nuclear decay sequences remains consistent. An aspect of radiometric 
aging that has caused greater concern among many biologists is the validity of assumptions made in radiometric age determination. These were outlined by Nevissi et al. (1996) as: "(1) during molting virtually all the calcium and associated nuclides are lost by the animal; (2) the carapace is calcified rapidly after molting, so that (3) addition or removal of radionuclides during the intermolt period is negligible."

Similar assumptions to those outlined by Nevissi et al. (1996) exist with all applications of radiometric aging for biological samples, yet they are seldom tested. Fenton et al. (1990) showed that an assumption of constant accumulation of ${ }^{226} \mathrm{Ra}$ into otoliths of a finfish, the blue grenadier (Macruronus novaezelandiae), was violated and thus radiometric aging could not be applied. Le Foll et al. (1989) used radiometric techniques to estimate the age of crustacean exoskeletons of known age, which provided a test of the extent of any addition or removal of radionuclides during the intermolt. Although they found reasonable agreement, some discrepancies were noted at extremes. We also examined the assumption of negligible addition or removal of radionuclides during the intermolt period in giant crabs by comparing age estimates for inner, middle, and outer layers of the carapace.

\section{Methods}

\section{Proportion of Females Reproducing}

A total of 342 female giant crabs were collected in April 1998 by a commercial fisher from areas adjacent to Bicheno off Tasmania's east coast. Sizes were from 92 to $208 \mathrm{~mm} \mathrm{CL}$, with the majority of animals $(N=327)$ larger than the size at $50 \%$ onset of maturity for this region, approximately $135 \mathrm{~mm}$ CL (Levings et al. 2001). This sample was collected prior to females extruding their eggs, which typically occurs in May (Gardner 1997). Fishers confirmed that no ovigerous females had been observed along the coast during the month of April. Samples were collected prior to oviposition to avoid bias in the ratio of reproductively active to inactive females, as ovigerous females have reduced catchability (Gardner 1998a).

The proportion of females in this sample that were reproductively active in the current year was assessed by the extent of ovarian development. Ovaries and spermathecae were viewed nondestructively using a $\mathrm{GM}^{\mathrm{TM}}$ computerized tomography scanner (CT-scanner; Gardner et al. 1998). Forty specimens were individually tagged and retained in tanks for a further 2 months until after oviposition to validate the ovarian classifications from the CT-scans. Ten animals were held in each $4 \mathrm{~m}^{3}$ tank, which were equipped with flow-through seawater supply and a sand substrate, approximately $150 \mathrm{~mm}$ deep, to assist in oviposition.

The proportion of females without developing ovaries was used as an indicator of the proportion molting by calculating the ratio of females without developing ovaries relative to those with developing ovaries. Confidence limits of this estimate were obtained by bootstrapping using 10,000 simulations. 


\section{Test of Assumptions of Radiometric Aging}

Six male giant crabs were captured from areas adjacent to Bicheno off Tasmania's east coast by a commercial fisher. Each specimen had shell with heavy wear (carapace-condition 3 in Gardner [1997]) and ranged between 199 and $223 \mathrm{~mm}$ CL. Large males were selected for this component due to their thick carapaces, which facilitated separation of the shell into different layers and the collection of large amounts of material. Radiometric analyses were by gamma spectroscopy, which is more rapid with larger samples.

The potential for addition or removal of radionuclides during the intermolt period was initially investigated by viewing the internal structure of the exoskeleton. Scanning electron microscopy (SEM) images were acquired in environmental mode with an ElectroScan ${ }^{\mathrm{TM}}$ ESEM2020 using water vapor as the imaging gas. The specimen chamber pressure was maintained at 5.0 torr.

Testing of the extent of exchange of radionuclides during the intermolt period by radiometric analysis was based on the hypothesis that material exchange would not occur uniformly through the exoskeleton. If exchange of radionuclides occurred between the exoskeleton and internal tissues, then we would expect younger age estimates from inner layers. Likewise, if exchange occurred with the environment, then age estimates from outer layers would be younger than those from the middle or inner layers.

Radiometric analysis was by gamma spectroscopy which avoided the chemical ingrowth stages described by Nevissi et al. (1996), although the principle of estimation through the analysis of the ${ }^{228} \mathrm{Th} /{ }^{228} \mathrm{Ra}$ ratio remained the same. Samples of the exoskeleton were prepared for analysis by grinding with hand-held grinder (Dremmel ${ }^{\mathrm{TM}}$ ) using a rotating tungsten steel bit. This was intended to separate material into coarse inner, middle, and outer layers of the exoskeleton, rather than anatomical layers of the integument. Samples were ground further in a standard ring mill prior to radiometric analyses, then weighed accurately into $55 \mathrm{ml}$ Petri dishes to completely fill the dish. Due to the absence of any prolonged gaseous stage in the decomposition chain, processing did not involve any steps of prolonged sealing. Samples were measured on a high-resolution Compton suppression gamma-ray spectrometer (Canberra Industries, Meriden, USA). The spectrometer consisted of an n-type high-purity germanium (HPGe) coaxial detector with relative efficiency of $50 \%$ surrounded by a sodium iodide (NaI) annular guard detector and removable NaI "plug" detector. The detector assembly was housed in a graded lead shield. Data analysis was performed using GENIE2000 software developed by Canberra Industries (Meriden, USA).

The activity of ${ }^{228} \mathrm{Ra}$ was determined by measuring its daughter ${ }^{228} \mathrm{Ac}$ at $911 \mathrm{keV}$ and the activity of ${ }^{228} \mathrm{Th}$ was determined by its progeny ${ }^{212} \mathrm{~Pb}$ at $238 \mathrm{keV}$ (Reyss et al. 1995). The age of the specimen was then determined according to the following equation: 
Age of carapace at death $=($ Isotopic Age $)-($ time between death and measurement)

where:

$$
\text { Isotopic Age }=-4.12 \times \operatorname{Ln}\left[1-0.669 \times \frac{(\text { Activity of }}{\left(\text { Activity of }{ }^{228} \mathrm{Th}\right)}\right]
$$

Isotopic Age is in years.

\section{Results}

\section{Proportion of Females Reproducing}

Retention of a subsample of 40 individually tagged female crabs in tanks after CT-scanning confirmed that the 35 females classed as possessing developing ovaries went on to extrude eggs, while the remaining 5 females with ovaries classed as undeveloped did not extrude eggs. This step validated the use of CT-scanning of ovaries for estimating the proportion of the sample that would reproduce in the current year.

Only two females did not appear to have mated, based on the appearance of the spermathecae; each of these were relatively small (92 and 142 $\mathrm{mm} \mathrm{CL}$ ). The proportion of females that were reproducing in the current year was lowest in smaller size categories, although stabilized in size classes greater than $140 \mathrm{~mm}$ CL (Fig. 1). The mean proportion of females that were not reproducing for all size classes greater than $140 \mathrm{~mm} \mathrm{CL}$ pooled was $11 \%$, which equates to approximately 1 in $9(N=327)$. Assuming the apparent link between molting and skipping reproduction holds true, this implies an intermolt period of 9 years for female giant crabs greater than $140 \mathrm{~mm}$ CL.

Estimates obtained by this indirect method of estimating intermolt duration appear affected by the constraining upper limit of $100 \%$ maturity of females. That is, random error around the estimate of the proportion reproducing appears to have a large influence on the estimate of intermolt duration. This is shown by the bootstrapped estimates of inferred intermolt duration which have a broad range (Fig. 2; lower 95\% confidence limit = 6.81 years, upper $=13.08$ years).

\section{Test of Assumptions of Radiometric Aging}

The validity of the assumption of no addition or removal of radionuclides during intermolt was initially assessed by viewing samples of the carapace in cross section using SEM. General structure of the exoskeleton was similar to that described by Stevenson (1985) with the epicuticle, pre-ecdysal procuticle, and principal layer of the procuticle calcified and formed of laminae parallel with the surface (Fig. 3A). Fine canals of around $2 @ \mathrm{~m}$ in diameter run perpendicular to the surface and appeared to be associated with tegumental glands (Fig. 3B). No structures that suggest that material 


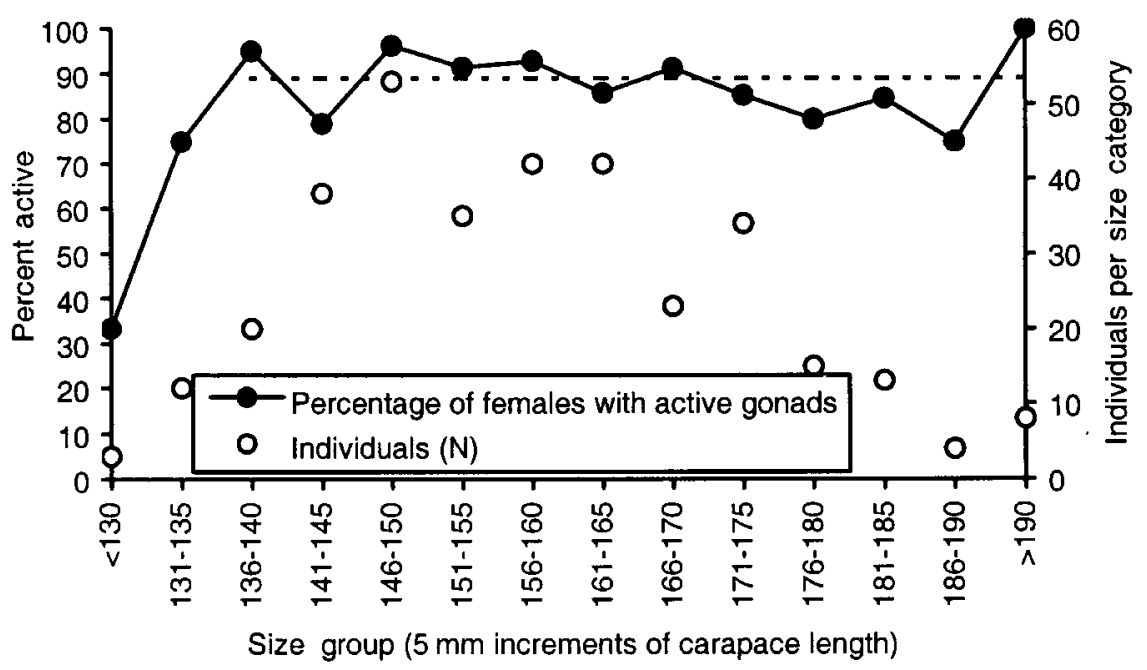

Figure 1. The proportion of females with ovaries classed as active in relation to carapace length. Classification of ovaries as active or inactive was based on CT-scans. Mean proportion of females greater than $140 \mathrm{~mm}$ CL participating in reproduction in the year of sampling was $89 \%$ (dashed line).

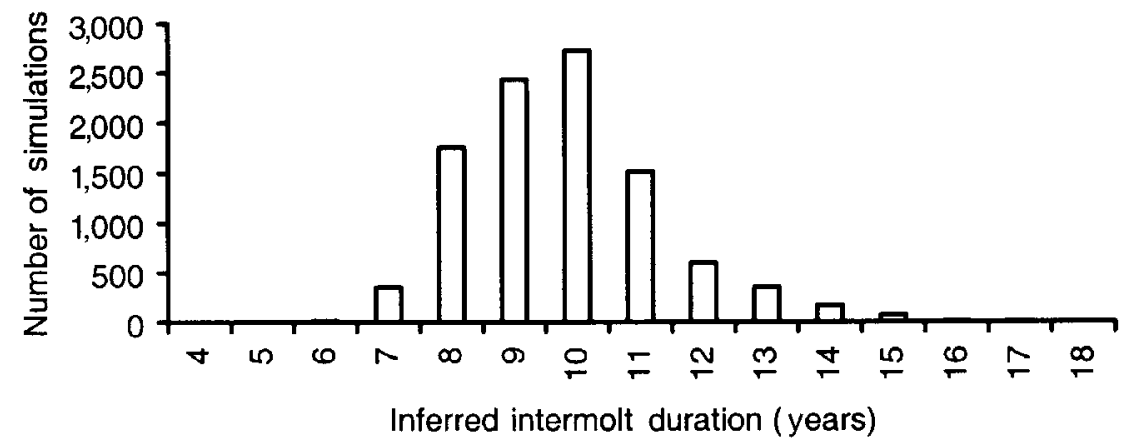

Figure 2. Bootstrapped simulations of the inferred intermolt duration based on the proportion of females without developing ovaries. 
is exchanged within the carapace were present, such as the canaliculi involved in cycling of mammalian bone (Junqueira and Carneiro 1983).

Radiometric results presented here are preliminary as they are based on only 18 analyses (3 layers for each of 6 crabs; Fig. 4) and further analyses are in progress. Estimates for these individuals ranged between 2 and 5 years. Although the sample size is small, there appears to be no significant difference in age estimates between layers in most specimens. This suggests that there was no material exchanged within the carapace during intermolt. In contrast, different age estimates between layers were observed in two specimens (numbers 1 and 4). There was no systematic pattern between these sets of analyses; in one case the oldest estimate was from the outer layer, while the youngest estimate was from the outer layer in the other.

\section{Discussion}

The methods assessed here may contribute to our understanding of intermolt duration based on tag-recapture data. Measurement of the proportion of females reproducing produced intermolt duration estimates of around 9 years, although confidence limits were broad (ranging from 6.8 to 13.1 years). This estimate of intermolt duration corroborates that obtained from tagging data (McGarvey et al. 1999) and provides support for the conclusion of an exceptionally long intermolt duration in female giant crabs. The robust carapace of giant crabs, which can exceed $4 \mathrm{~mm}$ in thickness, also testifies to a protracted intermolt period.

The use of the proportion of females participating in reproduction to estimate intermolt could only be applied to species meeting a specialized set of criteria. These criteria include a well-defined reproductive season and the linking of molting to the reproductive cycle so that the two events are mutually exclusive. Estimates will have greater precision where the proportion of animals that are participating in reproduction does not approach the $0 \%$ or $100 \%$ bounds. This implies greatest precision where molting occurs every 2 or 3 years (closer to $50 \%$ of animals molting each year), rather than the more protracted intermolt of giant crabs which led to broader confidence limits around estimates.

Radiometric estimates of male intermolt period also corroborate data obtained through tagging. Our estimates from individual analyses of crabs, which all had worn carapaces, ranged between 2 and 5 years while McGarvey et al. (1999) estimated intermolt from tagging data to be around 4 years.

We attempted to evaluate the potential for error in these estimates of radiometric age caused by exchange of material during intermolt. The microscopic structure of the exoskeleton would suggest that regular turnover of material within the exoskeleton is unlikely, which is consistent with the process of endocuticle synthesis described by Stevenson (1985) and Skinner et al. (1992). Radiometric analyses also indicated that exchange of material during intermolt does not generally occur, although results 

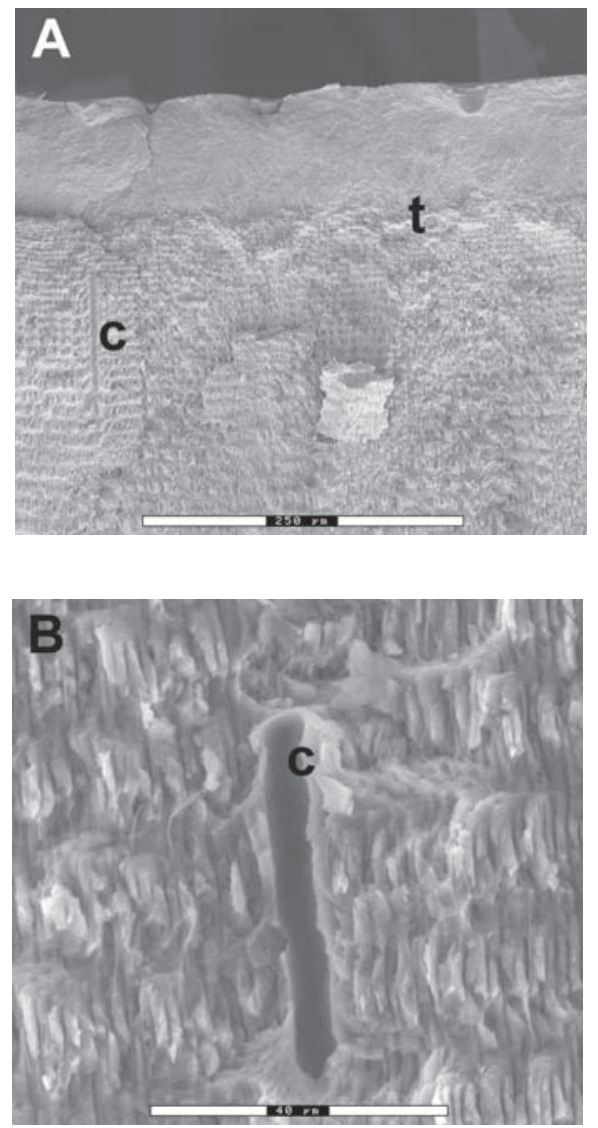

Figure 3. SEM images of the carapace of a male giant crab. Image (A) shows the transition (t) between the preecdysal procuticle and the principal layer (image taken at 200x, scale bar $=250 \mu \mathrm{m}$ ). Note the laminate structure with fine tegumental gland canals (c) running perpendicular to the surface. A canal (c) is shown in greater detail in image (B) (taken at $1,200 \times$, scale bar $=40 \mu \mathrm{m}$ ). 


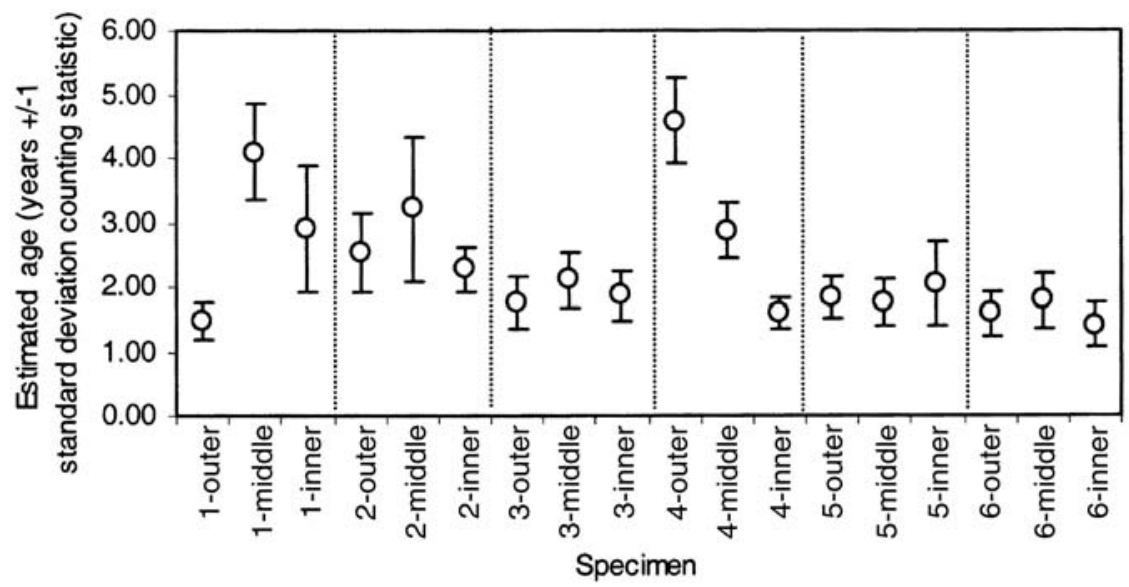

Figure 4. Radiometric estimates of shell age for inner, middle, and outer layers of the carapace of male giant crabs.

were not conclusive given that two specimens had significantly different age estimates from different layers. The lack of any consistent pattern between these two specimens indicates that the cause of the differing age estimates is more likely due to contamination of samples, rather than a biological effect. Further analyses are under way to increase the number of samples with the aim of resolving this issue.

Radiometric aging studies are often constrained by the prolonged processing times required for chemical ingrowth and measurement with total processing time in excess of one year. Consequently, the total number of analyses undertaken is generally small; Nevissi et al. (1996) reported results from five analyses, Le Foll et al. (1989) reported results from nine analyses, and Bennett and Turekian (1984) reported results from four analyses. The gamma-spectroscopic method applied here was more direct with specimen processing limited to grinding and weighing, and measurement of the ${ }^{228} \mathrm{Th} /{ }^{228} \mathrm{Ra}$ ratio determined in as little as a single day. Although this method requires specialized equipment, it offers the potential for broader application to crustacean research.

\section{Acknowledgments}

The authors are grateful for the contribution of David Steele to Electron Microscopy components, and Michel Bermudes and Philippe Ziegler for technical help. Peter Barrett (Tasmanian Sealife), Theo Hairon (Galaxy Fishing), and Michael White generously assisted through the supply of specimens. Jean Louis Reyss and Daniel Latrouite provided advice on gamma 
spectroscopy. Hobart Radiology donated CT-scanning equipment and staff time to the project. Rick McGarvey helped improve the manuscript. Financial support was provided by the Australian Institute of Nuclear Science and Energy, the Australian Research Council, The Tasmanian Department of Primary Industry and Fisheries, and the Tasmanian giant crab industry.

\section{References}

Andrews, A.H., K.H. Coale, J.L. Nowicki, C. Lundstrom, Z. Palacz, E.J. Burton, and G.M. Cailliet. 1999. Application of an ion-exchange separation technique and thermal ionization mass spectroscopy to ${ }^{226}$ Ra determination of long-lived fishes. Can. J. Fish. Aquat. Sci. 56:1329-1338.

Bennett, J.T., and K.K. Turekian. 1984. Radiometric ages of brachyuran crabs from the Galapagos spreading-centre hydrothermal ventfield. Limnol. Oceanogr. 29:1088-1091.

Fenton, G.E., D.A. Ritz, and S.A. Short. 1990. ${ }^{210} \mathrm{~Pb} /{ }^{226} \mathrm{Ra}$ disequilibria in otoliths of blue grenadier, Macruronus novaezelandiae; problems associated with radiometric ageing. Aust. J. Mar. Freshw. Res. 41:467-473.

Gardner, C. 1997. Effect of size on reproductive output of giant crabs Pseudocarcinus gigas (Lamarck): Oziidae. Aust. J. Mar. Freshw. Res. 48:581-587.

Gardner, C. 1998a. The Tasmanian giant crab fishery: A synopsis of biological and fisheries information. Tasmanian Department of Primary Industry and Fisheries Report 43. 40 pp.

Gardner, C. 1998b. The larval and reproductive biology of the giant crab. Ph.D. thesis, University of Tasmania, Hobart, Tasmania, $333 \mathrm{pp}$.

Gardner, C., M. Rush, and T. Bevilacqua. 1998. Nonlethal imaging techniques for crab spermathecae. J. Crustac. Biol. 18:64-69.

Junqueira, L.C., and J. Carneiro. 1983. Basic histology, 4th edition. Lange Medical Publications, Los Altos, California. 510 pp.

Le Foll, D., E. Brichett, J.L. Reyss, C. Lalou, and D. Latrouite. 1989. Age determination of the spider crab Maja squinado and the European lobster Homarus gammarus by ${ }^{228} \mathrm{Th} /{ }^{228} \mathrm{Ra}$ chronology: Possible extension to other crustaceans. Can. J. Fish. Aquat. Sci. 46:720-724.

Levings, A., B.D. Mitchell, T. Heeren, C. Austin, and J. Matheson. 1996. Fisheries biology of the giant crab (Pseudocarcinus gigas, Brachyura, Oziidae) in southern Australia. In: High latitude crabs: Biology, management, and economics. University of Alaska Sea Grant, AK-SG-96-02, Fairbanks, pp. 125-151.

Levings, A., B.D. Mitchell, R. McGarvey, J. Matthews, L. Laurenson, C. Austin, T. Heeren, N. Murphy, A. Miller, M. Rowsell, and P. Jones. 2001. Fisheries biology of the giant crab (Pseudocarcinus gigas). Final report to the Fisheries Research and Development Corporation, 93/220 and 97/132. 388 pp.

McGarvey, R., J.M. Matthews, and A.H. Levings. 1999. Yield-, value-, and egg-perrecruit of giant crab, Pseudocarcinus gigas. South Australian Research and Development Institute Report. 73 pp. 
McGarvey, R., A.H. Levings, and J.M. Matthews. In press. Moulting growth of Australian giant crab (Pseudocarcinus gigas). Aust. J. Mar. Freshw. Res.

Nevissi, A., J.M. Orensanz, A.J. Paul, and D.A. Armstrong. 1996. Radiometric estimation of shell age in Chionoecetes spp. from the eastern Bering Sea, and its use to interpret shell condition indices: Preliminary results. In: High latitude crabs: Biology, management, and economics. University of Alaska Sea Grant, AK-SG-96-02, Fairbanks, pp. 389-396.

Reyss, J.L., S. Schmidt, F. Legeleux, and P. Bonte.1995. Large, low background welltype detectors for measurements of environmental radioactivity. Nucl. Instr. and Meth. in Phys. Res. A 357:391-397.

Sheehy, M.R.J. 1992. Lipofuscin age-pigment accumulation in the brains of ageing field- and laboratory-reared crayfish Cherax quadricarinatus (von Martens) (Decapoda: Parastacidae). J. Exp. Mar. Biol. Ecol. 161:79-89.

Sheehy, M., N. Caputi, C. Chubb, and M. Belchier. 1998. Use of lipofuscin for resolving cohorts of western rock lobster (Panulirus cygnus). Can. J. Fish. Aquat. Sci. 55:925-936.

Skinner, D.M., S.S. Kumari, and J.J. O’Brien. 1992. Proteins of the crustacean exoskeleton. Am. Zool. 32:470-484.

Stevenson, J.R. 1985. Dynamics of the integument. In: D.E. Bliss and L.H. Mantel (eds.), The biology of Crustacea, Vol. 9. Academic Press, New York, pp. 1-42.

Wahle, R.A., O. Tully, and V. O’Donovan. 1996. Lipofuscin as an indicator of age in crustaceans: Analysis of the pigment in the American lobster Homarus americanus. Mar. Ecol. Prog. Ser. 138:117-123. 